\title{
Enhancement of porous silicon photoluminescence using vanadium pentoxide $\left(\mathrm{V}_{2} \mathrm{O}_{5}\right)$ treatment
}

\author{
L. Derbali ${ }^{1}$ and H. Ezzaouia \\ Photovoltaïc laboratory, Research and Technology Center of Energy, Technopôle de Borj-Cédria. BP 95 Hammam-Lif \\ 2050, Tunisia
}

\begin{abstract}
A new method has been developed to improve the photoluminescence intensity of porous Silicon PS. In this treatment we used vanadium, for the first time, to passivate porous silicon. Thermal evaporation of $\left(\mathrm{V}_{2} \mathrm{O}_{5}\right)$ onto PS layer, followed by a thermal treatment at $100^{\circ} \mathrm{C}, 200^{\circ} \mathrm{C}, 300^{\circ} \mathrm{C}$ and $400^{\circ} \mathrm{C}$ for 15 min under oxygen flow, can increase the intensity of the photoluminescence of PS. Vanadium oxide covers the nanoparticles of silicon without changing the wavelength distribution of the optical excitation and emission spectra. Changes in the surface morphology induced by thermal treatment were investigated by atomic force microscope (AFM) showing an increase of the nanoparticles dimensions compared to the initial dimensions of the PS nanostructure. The reflection spectra of PS, before and after treatment with $\left(\mathrm{V}_{2} \mathrm{O}_{5}\right)$, performed in the 300-1200 nm wavelength range and compared to a virgin mc-Si wafer, showed an important decrease of the reflectivity by this new treatment.
\end{abstract}

\section{Introduction}

Light emission from silicon materials is an important achievement for the development of silicon-integrated optoelectronic devices, compatible with microelectronic technologies. Crystalline silicon (c-Si), being an indirect semiconductor, does not emit light efficiently. Many alternative materials have been proposed to improve the luminescence from silicon-based materials (see, for example [1]). The most widely studied of these materials is porous silicon (p-Si) [2]. p-Si shows a strong photoluminescence (PL) in the visible and infrared region of the optical spectrum. This luminescence can usually be seen with the naked eye [3] and is commonly attributed to quantum confinement effects [4]. Moreover, p-Si shows a blue shift in the optical absorption edge [5] that is typical in quantum-confined systems [6]. All these reasons have motivated intense research on the formation processes and properties of this material, and many new applications have been raised for $\mathrm{p}-\mathrm{Si}$ : from solar cells [7] and chemical sensors to biomaterials [8].

One of the reasons that helped p-Si to be so widely studied is the simplicity of its preparation methods. Porous silicon can be obtained from c-Si by electrochemical anodization in an aqueous hydrofluoric acid (HF) solution [9]. Ethanol may also be used to improve the wetting of the c-Si surface. We can use "stain etching"' technique to obtain p$\mathrm{Si}$, which is a pure chemical etching process in which other chemical species are added to the HF aqueous solution, e.g. nitric acid $\left(\mathrm{HNO}_{3}\right)$ [10]. In this case, the $\mathrm{HNO}_{3}$ plays the role of the electron acceptor (or hole injector) and no electrode is needed. To improve the electro and the PL intensity of porous silicon PS, several passivation methods have been proposed. Another deleterious aspect to be avoided is that fresh PS has a large amount of dangling bonds [11] mixed with a surface hydrogen passivation [12]. Consequently, a metastable chemical composition of the porous surface is observed when it is exposed to the atmosphere [12]. This behavior affects the charge transport properties of the porous surface. Also, the presence of rapid recombination centers in the surface of the fresh PS samples affects the values of the solar cell efficiency for devices based on this material [13-/14]. Therefore, to achieve high and stable efficiency values, it is necessary to passivate the porous surface in order to avoid the formation of fast recombination centers as a consequence of the stain etching. Besides, the passivated coatings must maintain low reflectance values in the visibleIR range.

Many materials such as silver, gold and the transparent conducting oxides such an indium tin oxide, were tested and proved their ability to improve the PS properties. Various metals are deposited onto the PS surface by immersion plating or by dipping the surface into a solution containing metal ions such as $\mathrm{Ag} \mathrm{[15],} \mathrm{Cu}$ [16] and [17] and $\mathrm{Pd} \mathrm{[16].}$

\footnotetext{
${ }^{1}$ e-mail : rayan.slat@yahoo.fr
} 
In this work, we present a study of the possibility to enhance the PS photoluminescence intensity using vanadium oxide deposited after the evaporation of vanadium pentoxide $\left(V_{2} O_{5}\right)$.

\section{Experiment details}

Substrates used in this work were manufactured using p-type multicristalline silicon wafers with a resistivity of about $0,5-2 \Omega . c m$. The wafers were first dipped in an acid mixture (HF: $\left.16 \%, \mathrm{HNO}_{3}: 64 \%, \mathrm{CH}_{3} \mathrm{COOH}: 20 \%\right)$ for a few seconds in order to remove mechanical damage and then to obtain a cleaned surface. (PS) films were formed by the stain-etching technique using $\left(\mathrm{HF} / \mathrm{HNO}_{3} / \mathrm{H}_{2} \mathrm{O}\right)$ solution with $(1: 3: 5)$ volume composition [18]. Vanadium pentoxide $\left(\mathrm{V}_{2} \mathrm{O}_{5}\right)$ powder was evaporated onto the front side of samples, with a thickness of about $310 \mathrm{~nm}$. The wafers were then annealed in an infrared furnace for $20 \mathrm{~min}$ at temperatures in a range of $100-400{ }^{\circ} \mathrm{C}$ in dry $0_{2}$. The surface morphology was investigated by Atomic Force Microscope AFM, The reflectivity spectra were realized using LAMBDA 950 UV/Vis/NIR Spectrophotometer equipped with an integrating sphere. PL spectroscopic analyses of porous silicon before and after treatment with vanadium oxide were performed at ambient temperature with $4880 \mathrm{~A}^{\circ}$ laser.

\section{Results and discussion}

Figure $(1,2)$ shows (3D) atomic force microscopy (AFM) topography of porous silicon PS layer before and after treatment with vanadium oxide, to make comparison. Measurements revealed the surface morphology and nanostructure properties of the surface coatings. Scans were taken under the contact mode and over areas of $5 \mu \mathrm{m} * 5 \mu \mathrm{m}$ for root mean square (RMS) surface roughness calculation. It is remarkable to note that, the AFM data indicate a nanostructured grains which depends on substrate temperature. The increase in surface roughness with increasing substrate temperature is due to the growth of grains with preferred orientations and increasing in particle size. Evaporated vanadium pentoxide $\left(\mathrm{F}_{\mathrm{g}}\right)$ envelop crystallites of the porous silicon structure which augument the grains size as shown in (AFM) images, figure 2, and depending on the thermal treatment profil. The temperature of the film increases in the heating process, which will enhance the mobility of molecules or ions in the film. The movement of molecules or ions may induce the crystallization and the variation of surface morphology of the film [19]. The crystallite size and surface roughness are shown in Table 1.

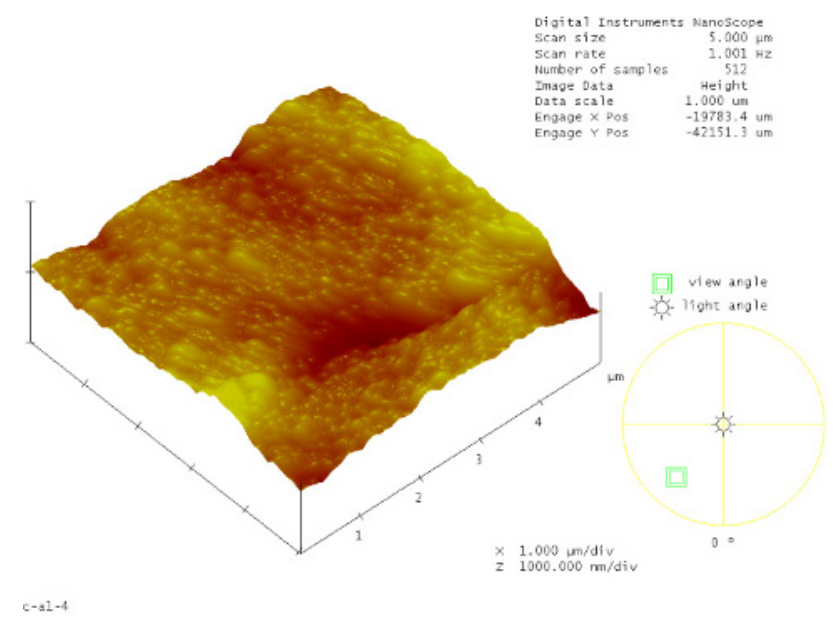

Fig. 1. (3D)AFM topograpgy of an unteated PS. 

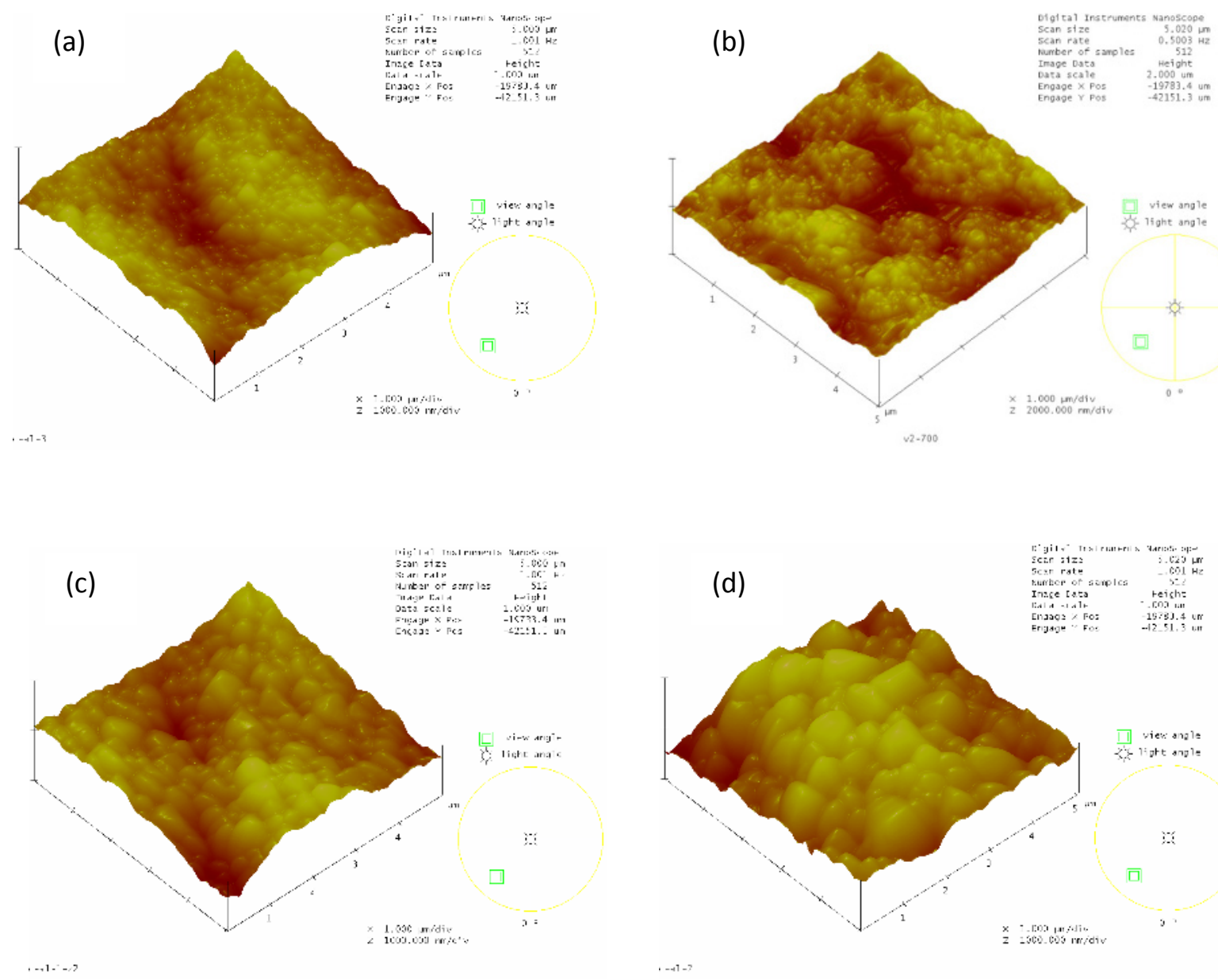

Fig. 2. (3D) AFM topography after $\left(\mathrm{V}_{2} \mathrm{O}_{5}\right)$ evaporation onto PS layer and thermally treated at: (a) $100^{\circ} \mathrm{C}$, (b) $200^{\circ} \mathrm{C},(\mathrm{c}) 300^{\circ} \mathrm{C},(\mathrm{d})$ $400^{\circ} \mathrm{C}$.

The grain size increased with increasing substrate temperature and was found to be around $153.64 \mathrm{~nm}$ for the films deposited and treated at $400^{\circ} \mathrm{C}$. This indicates that the film growth process is thermally activated. Furthermore, it is evident from the AFM images that the shape of the grains was also changing with the increase in substrate temperature in addition to the grain size, as shown in figure $(3,4)$. AFM cartography, show that vanadium oxide thin film covers the entire Si nanocrystallites which results in overall increase in crystallite size [20]. RMS roughness of the as-deposited film increases from 20820 to $133630 \mathrm{~nm}^{2}$ and the average grain size increase from 83.846 to $153.64 \mathrm{~nm}$, as shown in table 1. Both RMS roughness and average surface grain size of obtained films, after thermal cycling, are much greater than those of the untreated porous silicon and get higher when temperature rises.

Table 1. RMS surface roughness and average surface grain size of the films with different thermal treatments.

\begin{tabular}{|l|c|c|}
\hline Thermal treatment & $\begin{array}{c}\text { Average grain size } \\
\left(\mathbf{n m}^{2}\right)\end{array}$ & $\begin{array}{c}\text { RMS Surface roughness } \\
(\mathbf{n m})\end{array}$ \\
\hline Untreated (PS) & 20820 & 83.846 \\
\hline $100^{\circ} \mathrm{C}$ & 25177 & 118.10 \\
\hline $200^{\circ} \mathrm{C}$ & 74727 & 137.30 \\
\hline $300^{\circ} \mathrm{C}$ & 89688 & 170.80 \\
\hline $400^{\circ} \mathrm{C}$ & 133630 & 153.64 \\
\hline
\end{tabular}




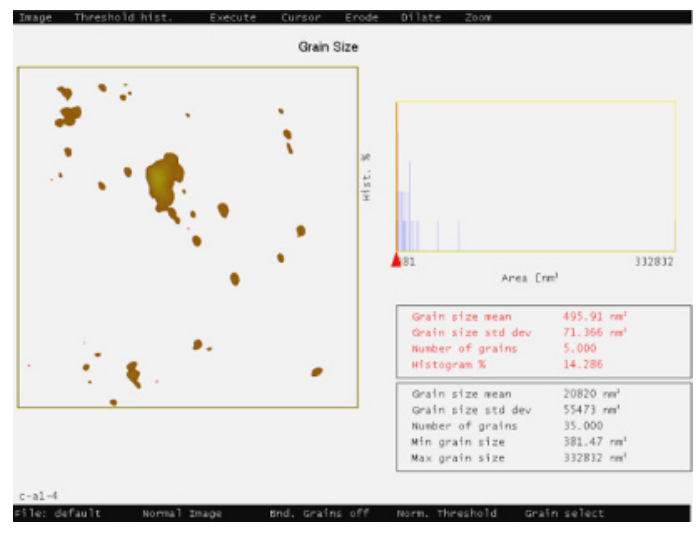

Fig. 3. nanocristallites size from AFM data of untreated PS.
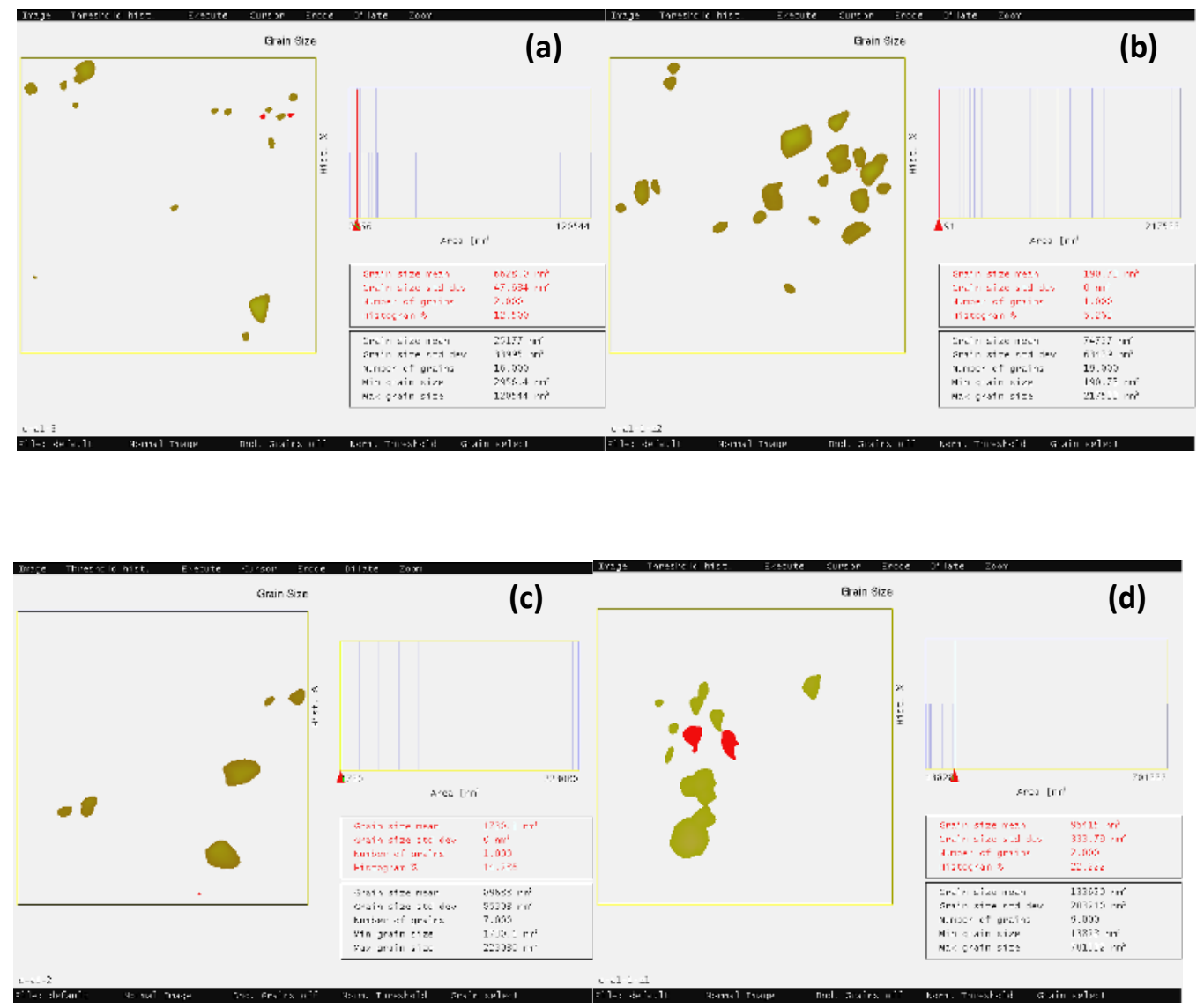

Fig. 4. Nanocristallites size from AFM data of treated PS/V structure at (a) $100^{\circ} \mathrm{C}$, (b) $200^{\circ} \mathrm{C}$, (c) $300^{\circ} \mathrm{C}$, (d) $400^{\circ} \mathrm{C}$.

Figure 5 shows the photoluminescence PL spectra of the samples thermally treated at different temperatures ranging between $100^{\circ} \mathrm{C}$ and $400^{\circ} \mathrm{C}$ under light excitation at $330 \mathrm{~nm}$. The sample treated at $400^{\circ} \mathrm{C}$ exhibits the highest PL intensity. When increasing temperature from $100^{\circ} \mathrm{C}$ to $400^{\circ} \mathrm{C}$, PL shows an increase of the peak intensity, as shown in figure 5. The Diffusion of vanadium oxide into the PS structure augments whenever increasing temperature, which explains clearly the dependence of the photoluminescence intensity with thermal treatment. The PL peak position does not present a change after treatment. We suggest that the deposition of vanadium oxide leads to an efficient passivation of the majority of silicon dangling bonds present into PS structure. The PL enhancement is due to the vanadiumpassivation of the PS layer. The surface passivation can reduce the surface recombination velocity, resulting in an enhancement of the PL intensity. 


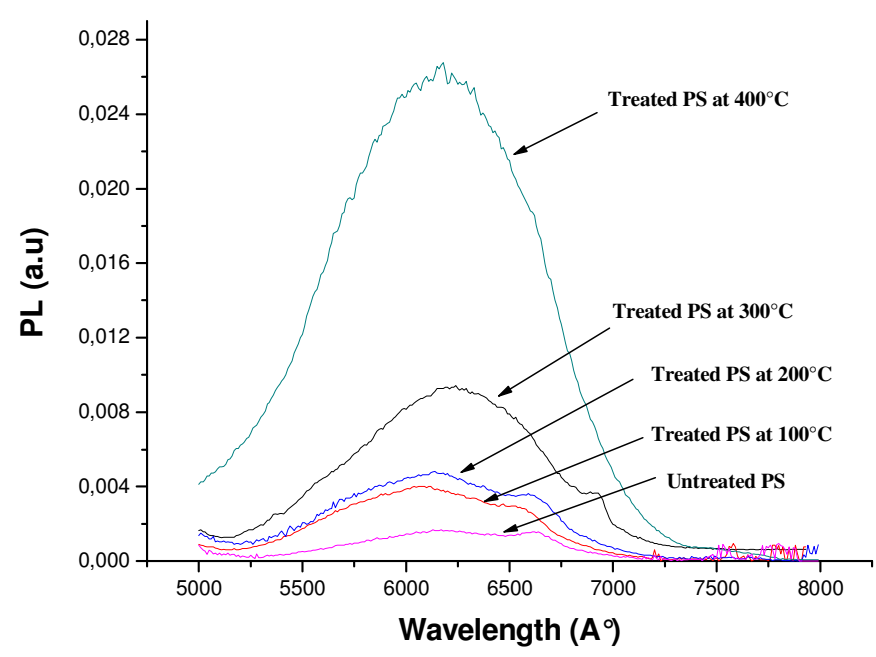

Fig. 5. Photoluminescence spectra of treated Porous silicon compared to an untreated PS wafer.

Vanadium oxide thin film deposited onto porous silicon layer is an adequate method to passivate the PS structure, which is needed to assure the stability of the optoelectronic properties of a device based on PS submitted to ambient conditions. When it undergoes a thermal treatment, vanadium will diffuse into PS structure and surrounds each nanocristallite, acting as a passivation layer for each crystallite, and then, diminishing the large amount of dangling bonds in the PS layer.

Figure 6 shows the reflectivity spectra of porous silicon, treated porous silicon under $400^{\circ} \mathrm{C}$ after $\left(V_{2} O_{5}\right)$ evaporation and reference wafer, performed in the 300-1200 nm spectral range. We choose to compare reflectance of wafer treated at $400^{\circ} \mathrm{C}$ which exhibits the highest photoluminescence PL intensity. Compared to the reference untreated wafer, both reflectivity of the PS layer and treated PS with vanadium oxide at $400^{\circ} \mathrm{C}$ exhibit lower reflectance in the whole wavelength range.

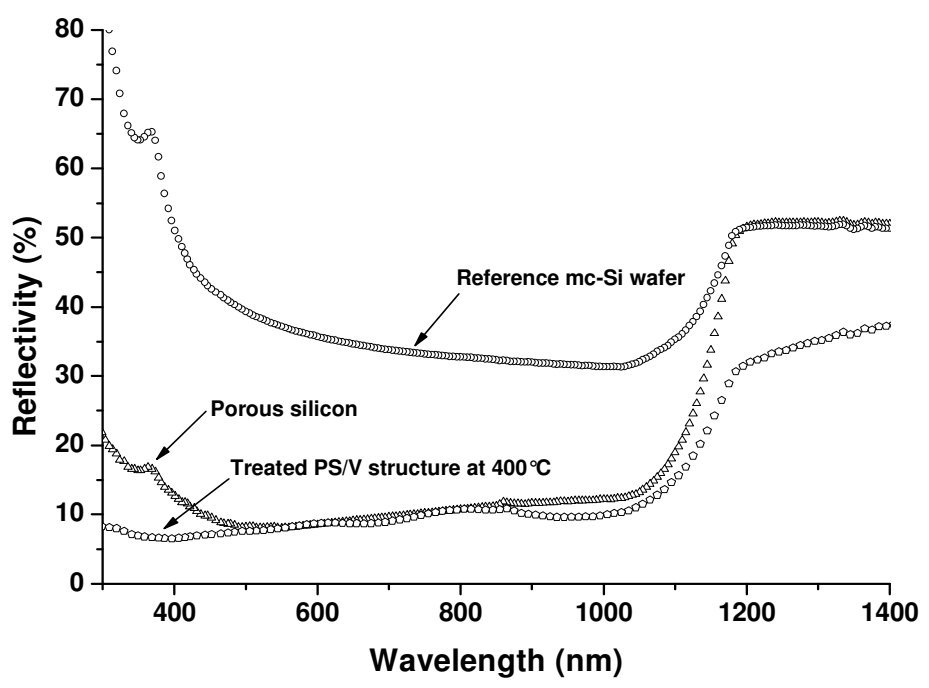

Fig. 6. Reflectivity spectra of untreated PS and treated PS/V structure at $400^{\circ} \mathrm{C}$, compared to a reference mc-Si wafer.

In the range of $300-500 \mathrm{~nm}$, a significant decrease of reflectivity has been obtained for sample treated at $400^{\circ} \mathrm{C}$ compared to the untreated PS structure reflectance. The independence of the reflectivity as a function of wavelength shows that the evaporated $\left(\mathrm{V}_{2} \mathrm{O}_{\mathrm{5}}\right)$ had no effect on this energy range. The important decrease of the reflectivity is related to the geometry modification of the nanostructures and roughness. We can therefore conclude that vanadium passivation increases the absorption of high energies. 


\section{Conclusion}

The influence of vanadium oxide deposition onto the porous silicon followed by thermal treatments has been discussed. AFM cartography shows that deposited vanadium oxide films diffuse into PS structure after annealing samples, which leads to cover the entire silicon nanocrystallites and raise the crystallite size. The experimental results in this study suggest a possibility of an efficient passivation of porous silicon by means of the incorporation of vanadium oxide, which induces a spectacular passivation of the silicon nanoparticles in the PS structure. The enhancement of PL and reflectivity are presented and discussed.

\section{Reference}

1. R. Soref, MRS Bull. 23 (4) 20; S. Coffa, G. Franzo, F. Priolo, MRS Bull. 25; L. Tsybeskov, MRS Bull. 33; E.A. Fitzgerald, L.C. Kimerling, MRS Bull. 39 (1998).

2. A.G. Cullis, L.T. Canham, P.D.J. Calcott, J. Appl. Phys. Lett. 82909 (1997).

3. R.E. Marotti, A. Rondoni, E. Quagliata, E.A. Dalchiele, Phys. Status Solidi (B) 220319 (1999).

4. L.T. Canham, Appl. Phys. Lett. 571046 (1990).

5. V. Lehmann, U. G. osele, Appl. Phys. Lett. 58856 (1991)

6. A.D. Yoffee, Adv. Phys. 43173 (1993).

7. L. Kore, G. Bosman, Sol. Energy Mater. Sol. Cells 5731 (1999)

8. L. Canham (Ed.), Properties of Porous Silicon, EMIS Data reviews Series, No. 18, INSPEC, London, (1997).

9. R.L. Smith, S.D. Collins, J. Appl. Phys. 71 R1 (1992).

10. J. Sarathy, S. Shih, K. Jung, C. Tsai, K.-H. Li, D.-L. Kwong, J. Campbell, S.-L. Yau, J. Bard, Appl. Phys. Lett. 601532 (1992).

11. A. Grosman, C. Ortega, in: G. Amato, C. Delerue, H.J. von Bardeleben (Eds.), Structural and Optical Properties of Porous Silicon Nanostructures, Gordon and Breach, London, 5 (1997).

12. A. Venkateswara, F. Ozanam, J.N. Chazalviel, J. Electrochem. Soc. 138153 (1991).

13. W. Theiss, S. Hilbrich, R. Arens-Fisher, M.G. Berger, H. Munder, in: G. Amato, C. Delerue, H.J. von Bardeleben (Eds.), Structural and Optical Properties of Porous Silicon Nanostructures Gordon and Breach, London 5 (1997).

14. B. Wang, D. Wang, L. Zhang, T. Li, Thin Solid Films 29340 (1997).

15. R. Boukherroub, D.D.M. Wayner, G.I. Sproule, D.J. Lockwood and L.T. Canham, Nano Lett. 1, p. 713 (2001).

16. R. Boukherroub, D.D.M. Wayner and D.J. Lockwood, Appl. Phys. Lett. 81 (4) p. 601 (2002).

17. X.J. Li, De L. Zhu, Q.W. Chen and Y.H. Zhang, Appl. Phys. Lett. 74, p. 389 (1999).

18. M. Hassen, A. Ben Jaballah, M. Hajji, H. Rahmouni, A. Selmi, H. Ezzaouia, Mater. Sci. Eng. B $124-125297$ (2005).

19. F. Lai, L. Lin, Z. Huang, R. Gai, Y. Qu, Appl. Surf. Sci. 2531801 (2006).

20. R. Prabakaran, T. Monteiro, M. Peres, A.S. Viana, A.F. da Cunha, H. Águas, A. Gonçalves, E. Fortunato, R. Martins and I. Ferreira, Thin Solid Films 5158664 (2007). 